\title{
Abnormal Embryo Development and Efficient Embryo Rescue in Interspecific Hybrids, Oryza sativa $\times$ O. minuta and $O$. sativa $\times$ O. officinalis
}

\author{
Pannanee Rodrangboon ${ }^{1)}$, Pradit Pongtongkam ${ }^{2)}$, Saowanee Suputtitada ${ }^{2}$ and Taiji Adachi*3) \\ 1) Laboratory of Plant Breeding, Division of Applied Genetics and Biotechnology, Faculty of Agriculture, Miyazaki University, \\ 1-1 Gakuen Kibanadai Nishi, Miyazaki 889-2192, Japan \\ 2) Department of Genetics, Faculty of Science, Kasetsart University, Bangkok 10900, Thailand \\ 3) Laboratory of Plant Genes and Physiology, Division of Agricultural and Environmental Sciences, Graduate School of Agriculture \& \\ Biological Science, Osaka Prefecture University, 1-1 Gakuen-cho, Sakai, Osaka 599-8531, Japan
}

Interspecific hybrids between cultivated rice (Oryza sativa, 2n $=24, \mathrm{AA}$ ) and two wild species (O. minuta, $2 n=48$, BBCC and $O$. officinalis, $2 n=24, C C$ ) have been produced by cross pollination. The embryo development in these interspecific hybrids was observed to study the deterioration features in detail. All hybrids showed either abnormal embryo development with degenerating endosperm or embryo retardation itself. Abnormally developed embryos were observed by the end of 7 days after pollination and the percentage of abnormally developed embryos increased from 7 to 14 DAP. The embryos were excised at 7 to 14 DAP and cultured on MS medium supplemented with 1,3 and $5 \mathrm{mg} / \mathrm{l}$ benzylaminopurine, $1 \mathrm{~g} / \mathrm{l}$ casein hydrolysate, $0.8 \%$ agar and $3 \%$ sucrose. The optimal time for rescue turned out to be 11-14 DAP. There was a significant difference $(P=0.05)$ in the regeneration efficiency rate with rescue time but no significant difference with of culture medi$u m$ in these cross combinations. The $F_{1}$ hybrids were morphologically intermediate between their parents. All $F_{1}$ hybrid plants thus obtained were completely sterile. Chromosome doubling was attempted by treating $F_{1}$ hybrid tillers with colchicine to overcome their sterility. The morphology of the colchicine-treated $F_{1}$ plants closely resembled the female parent and fertility.

Key Words: Oryza sativa, O. minuta, O. officinalis, interspecific cross, embryo rescue.

\section{Introduction}

The wild Oryza species are a rich source of useful traits for rice improvement, such as resistance to insect-pests and diseases (Heinrichs et al. 1985, Sitch 1990). A number of important traits have been transferred from wild species into cultivated species by interspecific hybridization (Amante-

Communicated by K. Hattori

Received August 13, 2001. Accepted December 5, 2001.

*Corresponding author (e-mail: taijiada@plant.osakafu-u.ac.jp)
Bordeos et al. 1991, 1992, Jena and Khush 1989, 1990 Khush et al. 1990, Multani et al. 1994, Pongtongkam et al. 1997, Suputtitada et al. 1994, 2000). Hybridization between cultivated rice (AA genome) and wild species sharing the same AA genome, such as $O$. nivara, O. rufipogon and $O$. longistaminata has been especially successful. However, more remote hybridization between $O$. sativa and the wild species, such as $O$. minuta (BBCC), O. officinalis $(\mathrm{CC})$ or $O$. brachyantha (FF) are difficult due to failure in embryo development. This inability of remote hybrids to undergo normal sexual reproduction might be overcome by embryo rescue, because the hybrid plants from remote parents have been achieved by embryo rescue (Amante-Bordeos et al. 1991, 1992, Jena and Khush 1989, Multani et al. 1994, Pongtongkam et al. 1997, Suputtitada et al. 1994, 2000).

The goal of our investigation was to identify features occurring at the post-fertilization stage of the interspecific cross of $O$. sativa cv. RD $6(2 \mathrm{n}=24$, AA $)$, a Thai rice as female parent and two species of wild rice, $O$. minuta $(2 \mathrm{n}=48, \mathrm{BBCC})$ and $O$. officinalis $(2 \mathrm{n}=24, \mathrm{CC})$, bearing resistance to brown plant hopper, green leaf hopper, whiteblack plant hopper blast and bacterial blight (Sitch et al. 1989, Vanghan and Sitch 1991) as the male parent and to rescue hybrid embryos with high efficiency. An attempt was also made to obtain fertile plants through colchicine treatment.

\section{Materials and Methods}

The maternal spikelets were emasculated by dipping in water of $42^{\circ} \mathrm{C}$ for 10 minutes before anthesis (6-8 a.m.). Pollination was performed with fresh pollen of the wild species at their anthesis. Cross-pollinated spikelets were covered with a glassine bag and collected at 1, 3, 5, 7, 9, 11 and 14 days after pollination (DAP). Normarski's differential interference contrast (DIC) microscopy was used for zygotic and post zygotic analysis as described by Suputtitada et al. (2000). Fertilization rate, embryo development and endosperm development were also recorded.

Hybrid embryos were detached from spikelets at 7-14 DAP. They were dissected with forceps, and were surfacesterilized with $70 \%$ ethanol for 2 minutes followed by $0.5 \%$ 
sodium hypochloride for 10-15 minutes and by rinsing with sterile water for 3 times 1 minute each. We cultured the excised embryos on MS agar medium (Murashige and Skoog, 1962) supplemented with benzylaminopurine at 1, 3 and $5 \mathrm{mg} / \mathrm{l}$, caseine hydrolysate $1 \mathrm{~g} / \mathrm{l}$ and $3 \%$ sucrose at $25 \pm 2{ }^{\circ} \mathrm{C}$. The seedlings were tillered on suitable medium with $0.3 \%$ activated charcoal for about 4 weeks (Suputtitada et al. 1994). Some parts of the plants were transplanted to grow in natural conditions, other parts were treated with colchicine to induce chromosome doubling. Four concentrations $(0.00,0.01,0.03,0.05 \%)$ of colchicine were added to the induction medium (MS liquid medium supplemented with benzylaminopurine at $1 \mathrm{mg} / \mathrm{l}$, caseine hydrolysate $1 \mathrm{~g} / \mathrm{l}$ and $3 \%$ sucrose). The $F_{1}$ plants were incubated for 3,5 and 7 days on this medium at $25 \pm 2{ }^{\circ} \mathrm{C}$ and then transferred to a colchicine-free medium for further culturing. The cultures were then incubated for 1 month, and thereafter transplanted to soil. The fertility, plant characteristics and chromosome number were studied.

Chromosome number was studied using root tips pretreated with distilled water for $3 \mathrm{~h}$ at $4^{\circ} \mathrm{C}$, followed by immersion in a $0.03 \%$ 8-hydroxy-quinolinol solution for $3 \mathrm{~h}$ at $25^{\circ} \mathrm{C}$ and fixed with acetic alcohol $(1: 3)$ for $24 \mathrm{~h}$ at $25^{\circ} \mathrm{C}$. After fixation, the root tips were treated with an enzyme solution containing 1.0\% Pectolyase Y23 and 2\% Cellulase Onozuka RS ( $\mathrm{pH} 4.0)$ for $3 \mathrm{~h}$ at $25^{\circ} \mathrm{C}$ and subsequently washed 3 times with distilled water. After treatment with $1 \mathrm{~N} \mathrm{HCl}$ for $10 \mathrm{~min}$, the root tips were squashed in $1 \%$ acetocarmine solution and analyzed microscopically.

\section{Results and Discussion}

\section{Embryo development}

Embryo development of self-pollinated $O$. sativa cv. RD 6 was used as a control for embryo development (Table 1). All embryo sacs contained a zygote at 1 DAP. The average diameter of the zygotes was $20 \mu \mathrm{m}$. In two thirds of these embryo sacs two endosperm nuclei were visible, the remaining one third had three to twelve nuclei. Until 2 DAP, the fertilized egg cell still remained at the zygote stage. The zygote started to divide after the endosperm nuclei had divided several times. At 3 DAP, the zygote developed into the proembryo stage (Fig. 1A). The average diameter of the proembryos was $30 \mu \mathrm{m}$. The endosperm nuclei were located at the periphery of the embryo sac within 7 DAP. At 7 DAP, the proembryo developed into the globular stage (Fig. 1B). However, most globular embryos were found from $9 \mathrm{DAP}$ on and the average diameter of globular embryos was $50 \mu \mathrm{m}$. On the $11 \mathrm{DAP}$, the embryos of $O$. sativa had grown into fully developed structures (Fig. 1C).

In cross-pollinations between $O$. sativa $\times O$. minuta and $O$. sativa $\times O$. officinalis, more than 250 embryo sacs of each were observed (Table 1). Fully developed embryos, similar to those in Fig. 1C, were not observed at 14 DAP in either cross-combination, even though retarded embryos were still alive. Embryo sacs contained either degenerated or retarded embryo. Both hybrid embryo sacs of $O$. sativa $\times O$. minuta and $O$. sativa $\times$ O. officinalis contained a zygote and primary endosperm at 3 DAP (Fig. 1D). The remainings of both combinations were still at the egg or zygotic stage. At 7 DAP, the hybrid embryo sacs only divided to multiple

Table 1. Embryo development in self- and cross-pollinated Oryza species

\begin{tabular}{|c|c|c|c|c|c|c|c|}
\hline \multirow{2}{*}{$\begin{array}{c}\text { Cross combination and } \\
\text { developmental stage of embryo }\end{array}$} & \multicolumn{7}{|c|}{ Days after pollination (DAP) } \\
\hline & 1 & 3 & 5 & 7 & 9 & 11 & 14 \\
\hline \multicolumn{8}{|l|}{ Self-pollination of $O$. sativa } \\
\hline Zygote & $20(100)^{1)}$ & $24(61.5)$ & $2(4.8)$ & 0 & 0 & 0 & 0 \\
\hline Proembryo & 0 & $15(38.5)$ & $40(95.2)$ & $19(48.7)$ & $3(7.9)$ & 0 & 0 \\
\hline Globular & 0 & 0 & 0 & $20(51.3)$ & $35(92.1)$ & $23(59.0)$ & 0 \\
\hline Fully differentiated & 0 & 0 & 0 & 0 & 0 & $16(41.0)$ & $55(100)$ \\
\hline Total & 20 & 39 & 42 & 39 & 38 & 39 & 55 \\
\hline \multicolumn{8}{|l|}{ O. sativa $\times O$. minuta } \\
\hline Zygote & $18(100)$ & $25(67.6)$ & $30(83.3)$ & $24(58.5)$ & $13(34.2)$ & $1(2.5)$ & 0 \\
\hline Proembryo & 0 & 0 & 0 & 0 & $7(18.4)$ & $10(25.0)$ & $2(3.8)$ \\
\hline Globular & 0 & 0 & 0 & 0 & 0 & $8(20.0)$ & $18(34.0)$ \\
\hline Fully differentiated & 0 & 0 & 0 & 0 & 0 & 0 & 0 \\
\hline Aborted & 0 & $12(32.4)$ & $6(16.7)$ & $17(41.5)$ & $18(47.4)$ & $21(52.5)$ & $33(62.2)$ \\
\hline Total & 18 & 37 & 36 & 41 & 38 & 40 & 53 \\
\hline \multicolumn{8}{|l|}{ O. sativa $\times O$. officinalis } \\
\hline Zygote & $18(100)$ & $24(65.9)$ & $29(81.1)$ & $22(54.3)$ & $10(26.3)$ & 0 & 0 \\
\hline Proembryo & 0 & 0 & 0 & 0 & $8(21.0)$ & $11(28.1)$ & 0 \\
\hline Globular & 0 & 0 & 0 & 0 & 0 & $6(15.6)$ & $18(34.5)$ \\
\hline Fully differentiated & 0 & 0 & 0 & 0 & 0 & 0 & 0 \\
\hline Aborted & 0 & $13(34.1)$ & 7 (18.9) & $19(45.7)$ & $20(52.7)$ & $23(56.3)$ & $35(65.5)$ \\
\hline Total & 18 & 37 & 36 & 41 & 38 & 40 & 53 \\
\hline
\end{tabular}

1) Number of embryo (percentage) 

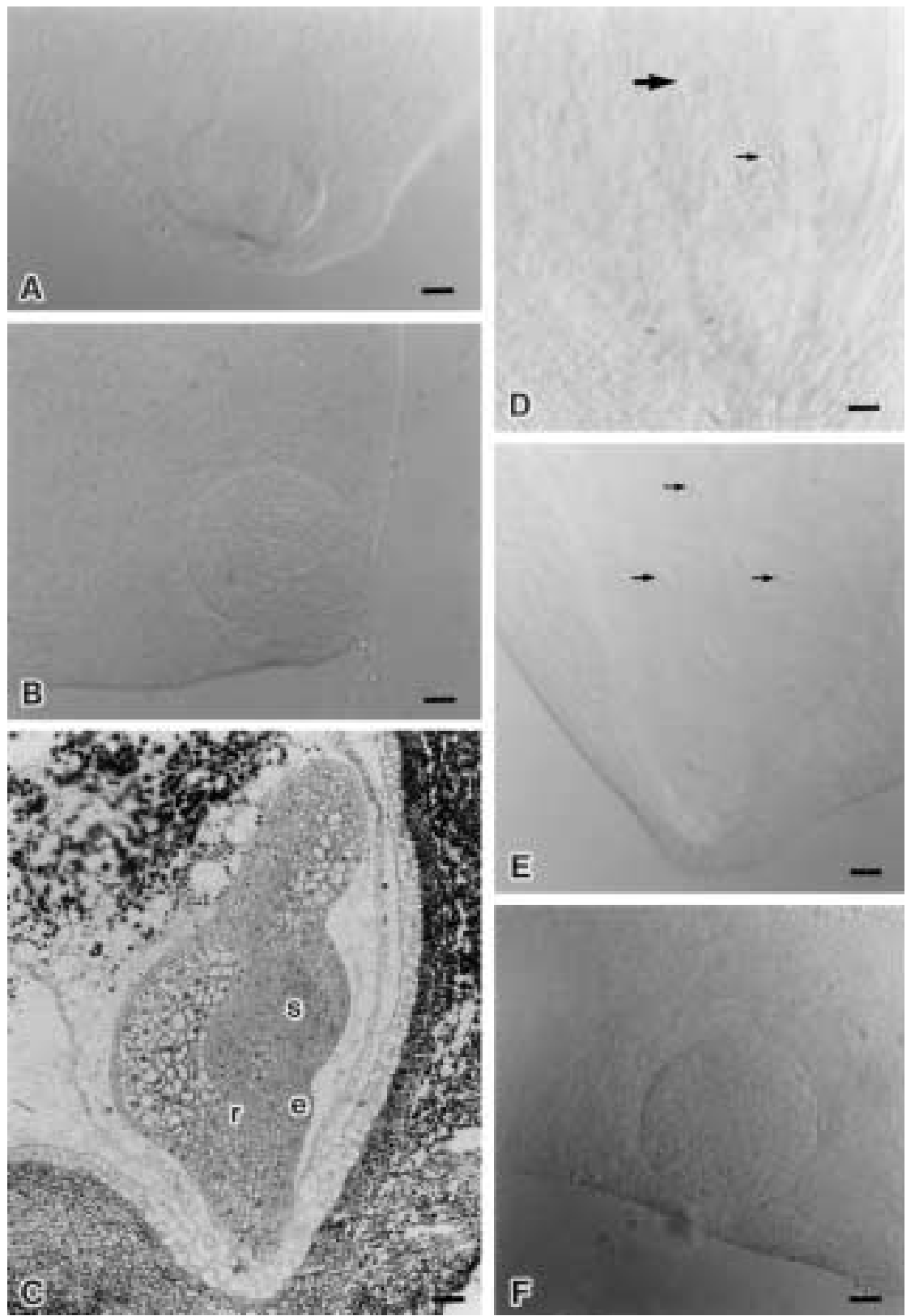

Fig. 1. Comparative development of embryo sac and embryo in self- and cross-pollinations at 3, 7 and 11 DAP. Normal development of proembryo at 3 DAP. (A). globular embryo at 7 DAP (B). fully differentiated embryo at 11 DAP (C). shoot apex (s), root apex (r) and epiblast (e). Abnormal development of $O$. sativa $\times$ O. minuta shows fertilized egg (small arrow) and primary endosperm nucleus (big arrow) at 3 DAP (D). multiple endosperm nuclei (arrows) at 7 DAP (E). still viable embryo at 11 DAP (F). Bar $=10 \mu \mathrm{m}$ in Fig. 1A, 1B and 1F, Bar $=20 \mu \mathrm{m}$ in Fig. 1D, Bar $=30 \mu \mathrm{m}$ in Fig. 1E, bar $=100 \mu \mathrm{m}$ in Fig. 1C.

endosperm nucleus and embryo development was delayed (Fig. 1E). At that time, the proembryos of control plants had developed to the globular stage. Globular stage embryos were found in both, O. sativa $\times O$. minuta (Fig. $1 \mathrm{~F}$ ) and $O$. sativa $\times$ O. officinalis, at $11 \mathrm{DAP}$.

When the developments in both interspecific combinations were compared with the self-pollinated $O$. sativa, retardation of embryo development and/or later embryo de- generation was obvious (Table 1). The interspecific hybrid embryo in both combinations showed a slower growth than that of the selfed one and its growth mostly stopped at the zygote and proembryo stage. At 11 DAP, the selfed embryo was usually a fully differentiated embryo while the interspecific hybrid embryo was just at the globular stage. Focussing on early developmental stages, we tried to elucidate the degradation procedure. As shown in Table 1, embryo sacs of 
$O$. sativa $\times O$. minuta and $O$. sativa $\times O$. officinalis remained as single cells, unfertilized or zygotic at $3 \mathrm{DAP}$, for $67.6 \%$ and $65.9 \%$, respectively. Development of embryos at 5 DAP was also delayed and sometimes even stopped short of 7 DAP. The percentage of aborted embryos increased from 7 to 14 DAP by more than $60 \%$. The endosperm failed to divide and degenerated by the end of 7 DAP. In both cross-combinations, we found that embryo development was much slower than that of the control and its growth mostly stopped at the globular stage at 11-14 DAP, while the control embryos had developed to full maturity. Several hybrid embryos were slimmed in shape and collapsed. This type of failure of embryo development occurred during endosperm formation. In some cases, an embryo could develop for several days in the absence of endosperm, but the differentiation of the organ had stopped.

Endosperm failed to divide and started to degenerate and later had only a few cells around the embryo. Some embryo sacs continued to develop with a small endosperm and some embryo sacs contained embryos without endosperm. In general, the endosperm is a tissue that provides nutrients to the developing embryo. After the degeneration of endosperm, the embryo is no longer supplied with nutrients. This deficiency causes embryo starvation and inhibition of further differentiation, causing embryo abortion. On the other hand, Cooper and Brink (1944) suggested that abnormal mitotic behavior of the endosperm nuclei causes seed collapse in Gramineae.

However, nutritional deficiency and abnormal mitotic behaviour of the endosperm nuclei could be due to problems of genetic incompatibility between two remote species. Chu and Oka (1970) reported that the $F_{1}$ embryos and endosperm begin to deteriorate at about 6 DAP in interspecific hybridization between $O$. sativa and $O$. longistaminata. When $O$. longistaminata was used as maternal parent, hybrid embryos failed to develop after 3 DAP. The authors said that these observations could be explained by the presence of a barrier controlled by a set of complementary dominant lethal genes. In genetic experiments, Sano and Kobayashi (1996) revealed that the incompatibility reaction is accomplished by factors from both the female and the male parent. Our results showed that the embryo abortion occurred at the early stage of embryo development hence they could not continue to differentiate. It seemed to be they could not develop in the absence of nutrients from endosperm and the consequence of genetic incompatibility caused both embryo and endosperm failed to develop.

\section{Embryo culture}

In total, 796 and 768 florets of $O$. sativa were pollinated with pollen grains of $O$. minuta and $O$. officinalis, respectively. Sixty seven florets with embryos were obtained in $O$. sativa $\times O$. minuta and 66 florets in $O$. sativa $\times O$. officinalis (Table 2). Hybrid embryos of 7 to 14 DAP were cultured on the medium. The percentage of embryos detached from maternal plants decreased with the increase of DAP in both cross-combinations as shown in Table 2. The causes due to endosperm were failure to divide and degeneration. In this experiment, we cultured embryos on MS medium supplemented with 1, 3 and $5 \mathrm{mg} / \mathrm{l}$ of BAP, notated as $\mathrm{C}_{0}, \mathrm{C}_{1}$ and

Table 2. Efficiency of embryo rescue in interspecific hybrids, O. sativa $\times$ O. minuta and $O$. sativa $\times$ O. officinalis

\begin{tabular}{|c|c|c|c|c|c|c|c|}
\hline $\begin{array}{l}\text { Embryo } \\
\text { excised } \\
\text { (DAP) }\end{array}$ & $\begin{array}{c}\text { No. of } \\
\text { pollination } \\
\text { florets (A) }\end{array}$ & $\begin{array}{c}\text { No. of } \\
\text { detached } \\
\text { embryos (B) }\end{array}$ & $\mathrm{B} / \mathrm{A}(\%)$ & Medium & $\begin{array}{c}\text { No. of } \\
\text { inoculated } \\
\text { embryos (C) }\end{array}$ & $\begin{array}{c}\text { No. of } \\
\text { regenerated } \\
\text { plants (D) }\end{array}$ & $\begin{array}{l}\text { Regeneration } \\
\text { efficiency } \\
\text { (D/C) }(\%)\end{array}$ \\
\hline \multicolumn{8}{|c|}{ O. sativa $\times$ O. minuta } \\
\hline & & & & $\mathrm{C}_{0}{ }^{1)}$ & 12 & 3 & 25.0 \\
\hline \multirow[t]{4}{*}{$7-10$} & 414 & 40 & 9.7 & $\mathrm{C}_{1}^{2)}$ & 13 & 4 & 30.0 \\
\hline & & & & $\mathrm{C}_{2}^{3)}$ & 15 & 6 & 40.0 \\
\hline & & & & Total & 40 & 13 & 32.5 \\
\hline & & & & $\mathrm{C}_{0}{ }^{1)}$ & 7 & 5 & 71.4 \\
\hline \multirow[t]{2}{*}{$11-14$} & 382 & 27 & 7.1 & $\mathrm{C}_{1}^{2)}$ & 9 & 5 & 55.6 \\
\hline & & & & $\mathrm{C}_{2}^{3)}$ & 11 & 5 & 45.5 \\
\hline Total & 796 & 67 & & Total & 27 & 15 & 55.6 \\
\hline \multicolumn{8}{|c|}{ O. sativa $\times$ O. officinalis } \\
\hline & & & & $\mathrm{C}_{0}^{1)}$ & 12 & 2 & 16.7 \\
\hline \multirow[t]{4}{*}{$7-10$} & 404 & 39 & 9.7 & $\mathrm{C}_{1}^{2)}$ & 13 & 4 & 30.8 \\
\hline & & & & $\mathrm{C}_{2}^{3)}$ & 14 & 4 & 28.6 \\
\hline & & & & Total & 39 & 10 & 25.6 \\
\hline & & & & $\mathrm{C}_{0}^{1)}$ & 9 & 5 & 55.6 \\
\hline \multirow[t]{2}{*}{$11-14$} & 364 & 27 & 7.4 & $\mathrm{C}_{1}{ }^{2)}$ & 9 & 4 & 44.4 \\
\hline & & & & $\mathrm{C}_{2}{ }^{3)}$ & 8 & 4 & 50.0 \\
\hline Total & 768 & 66 & & Total & 26 & 13 & 50.0 \\
\hline
\end{tabular}

1) MS medium containing $1 \mathrm{mg} / \mathrm{l}$ benzylaminopurine and casein hydrolysate $1 \mathrm{~g} / \mathrm{l}$

2) MS medium containing $3 \mathrm{mg} / \mathrm{l}$ benzylaminopurine and casein hydrolysate $1 \mathrm{~g} / \mathrm{l}$

3) MS medium containing $5 \mathrm{mg} / \mathrm{l}$ benzylaminopurine and casein hydrolysate $1 \mathrm{~g} / \mathrm{l}$ 
$\mathrm{C}_{2}$ medium, respectively. After one week, some immature embryos germinated. Regeneration efficiency ranged from $16.7 \%$ to $71.4 \%$ for both interspecific cross combinations. The average ratios of regeneration of 7-10 DAP culture were $32.5 \%$ and $25.6 \%$ for $O$. sativa $\times O$. minuta and $O$. sativa $\times$ O. officinalis, respectively. These ratios increased to $50.0 \%$ and $55.6 \%$ at $11-14$ DAP. In three types of medium, although the highest regeneration efficiency was observed in $\mathrm{C}_{0}$ medium, there was no significant difference among the three types of culture medium $(\mathrm{F}=0.24, \mathrm{P}=0.05$ in $O$. sativa $\times O$. minuta and $\mathrm{F}=0.06, \mathrm{P}=0.05$ in $O$. sativa $\times O$. officinalis). From comparison of the regeneration efficiency between 7-10 DAP and 11-14 DAP, there was no significant difference between the time to rescue in both combinations $(\mathrm{F}=9.11, \mathrm{P}=0.05$ in $O$. sativa $\times O$. minuta and $\mathrm{F}=13.12$, $\mathrm{P}=0.05$ in O. sativa $\times$ O. officinalis). It is concluded that the time point of rescue had a significant effect for the survival of the embryo. The optimal time to excise embryos for rescue was 11-14 DAP in both cross-combinations. These findings suggest that it might be able to rescue the embryo at the globular stage.

After culture for 3 weeks, phenolic compounds were found released in the medium. Therefore, the plants were transferred to fresh medium containing $0.3 \%$ activated charcoal to absorb phenolic compounds (Suputtitada et al. 1994). The regenerated plants developed well within 4 weeks and were transplanted to soil. Transplanted plants were easily acclimatized to the natural conditions. The $F_{1}$ hybrids were morphologically intermediate between their parents, such as panicle type and length, floret size and stigma color. However, they resembled the male parent in decending angle of flag leaf, presence of awn and shattering habit. The $\mathrm{F}_{1}$ hybrids had vigorous and profuse tillers (Fig. 2) but were completely sterile. The sterility results from genetic differences in structure and number of chromosomes.

\section{Chromosome doubling}

Chromosome doubling was attemped by treating $\mathrm{F}_{1}$ hybrid tillers with colchicine to overcome their sterility. The young $\mathrm{F}_{1}$ hybrid plants treated with $0.01 \%, 0.03 \%$ and 0.05 $\%$ colchicine for 3, 5 and 7 days showed different responses on the culture medium. The percentage of viability of the colchicine treated $F_{1}$ plants was decreased according to the increase of colchicine concentration and duration of treatment and ranged from $10.0 \%$ to $95.0 \%$ for both cross combinations as shown in Table 3 . In both cross-combinations, the plants treated with $0.01 \%$ colchicine for 3 days survived better than those given other treatments. The highest percentage of viability of the colchicine- treated $\mathrm{F}_{1}$ plants was $90.0 \%$ and $95.0 \%$ for $O$. sativa $\times$ O. minuta and $O$. sativa $\times$ $O$. officinalis, respectively. However, those treated with $0.05 \%$ colchicine for 7 days failed to survive in both crosscombinations. After transplanting into soil some tillers of the colchicine-treated $F_{1}$ plants produced panicles and seeds while some produced only panicles but set no seed. The morphology of the colchicine-treated $\mathrm{F}_{1}$ plants were closely
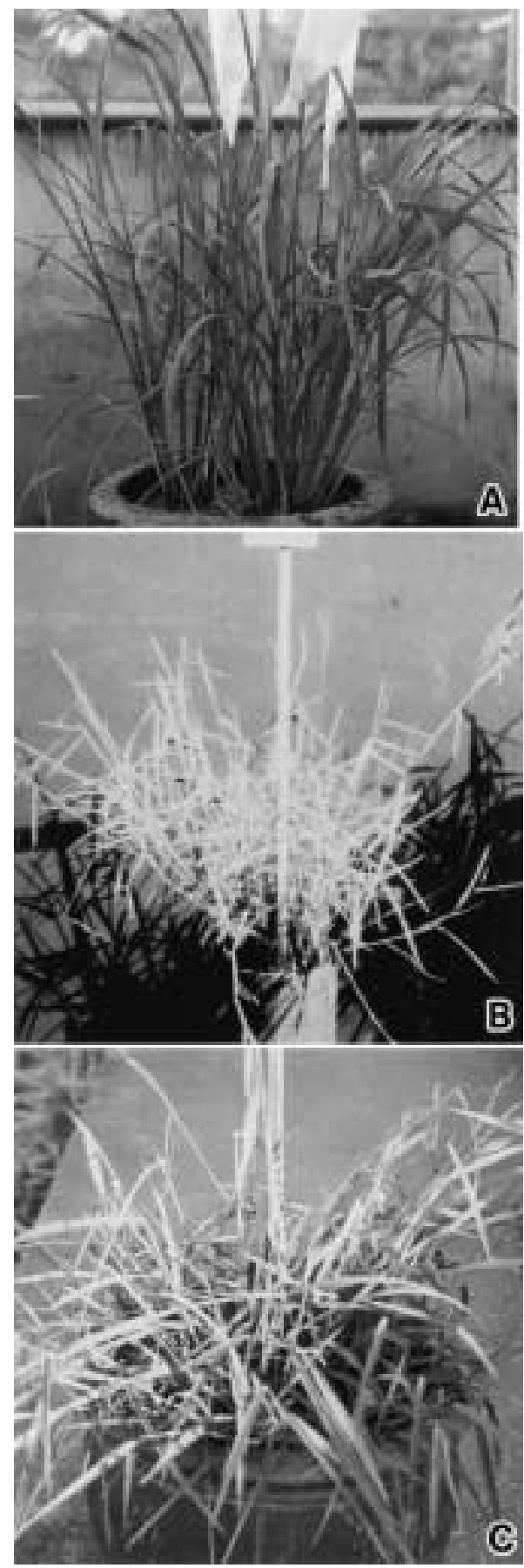

Fig. 2. Morphology of rice plant type at tillering stage. A. O. sativa, B. O. minuta, C. $\mathrm{F}_{1}$ hybrid of $O$. sativa $\times O$. minuta

resembled those of the female parent, such as plant type, panicle type and stigma color. The $\mathrm{F}_{1}$ hybrid plants not treated with colchicine were used as a control. They had a morphology intermediate between their parents and were completely sterile. This result implied that colchicine could change the morphology of the plant. The percentage of seed set ranged from $1.4 \%$ to $6.5 \%$ for both cross-combinations (Table 4). The highest percentage of seed set was observed in the plants treated with $0.01 \%$ colchicine for 5 days of 
Table 3. Percentage of viability of the colchicine-treated $F_{1}$ plants of interspecific hybrids, $O$. sativa $\times O$. minuta and $O$. sativa $\times O$. officinalis

\begin{tabular}{|c|c|c|c|c|}
\hline & tment & No. of plants & No. of viable & Viability ( 0 \\
\hline Duration & ntration (\%) & treated & plants & viavinty (/o) \\
\hline O. sativ & & & & \\
\hline 3 & 0.01 & 20 & 18 & 90.0 \\
\hline & 0.03 & 20 & 11 & 55.0 \\
\hline & 0.05 & 20 & 8 & 40.0 \\
\hline 5 & 0.01 & 20 & 12 & 60.0 \\
\hline & 0.03 & 20 & 7 & 35.0 \\
\hline & 0.05 & 20 & 3 & 15.0 \\
\hline 7 & 0.01 & 20 & 3 & 15.0 \\
\hline & 0.03 & 20 & 2 & 10.0 \\
\hline & 0.5 & 20 & - & - \\
\hline O. sativ & nalis & & & \\
\hline 3 & 0.01 & 20 & 19 & 95.0 \\
\hline & 0.03 & 20 & 13 & 65.0 \\
\hline & 0.05 & 20 & 9 & 45.0 \\
\hline 5 & 0.01 & 20 & 10 & 50.0 \\
\hline & 0.03 & 20 & 5 & 25.0 \\
\hline & 0.05 & 20 & 5 & 25.0 \\
\hline 7 & 0.01 & 20 & 4 & 20.0 \\
\hline & 0.03 & 20 & 3 & 15.0 \\
\hline & 0.5 & 20 & - & - \\
\hline
\end{tabular}

Table 4. Percentage of seed set in the colchicine-treated $\mathrm{F}_{1}$ plants of interspecific hybrids, $O$. sativa $\times$ $O$. minuta and $O$. sativa $\times O$. officinalis

\begin{tabular}{|c|c|c|c|c|c|}
\hline \multicolumn{2}{|c|}{ Colchicine treatment } & \multirow{2}{*}{$\begin{array}{c}\text { No. of } \\
\text { transplanted } \\
\text { plants }\end{array}$} & \multirow{2}{*}{$\begin{array}{c}\text { No. of fertile } \\
\text { plants }\end{array}$} & \multirow{2}{*}{$\begin{array}{l}\text { Percentage of } \\
\text { fertile plants }\end{array}$} & \multirow{2}{*}{$\begin{array}{c}\text { Percentage seed } \\
\text { set in fertile } \\
\text { plants }\end{array}$} \\
\hline Duration & tration $(\mathrm{w} / \mathrm{v}, \%)$ & & & & \\
\hline \multicolumn{6}{|c|}{ O. sativa $\times O$. minuta } \\
\hline \multirow[t]{3}{*}{3} & 0.01 & 20 & 4 & 20.0 & 2.3 \\
\hline & 0.03 & 11 & 1 & 9.1 & 5.2 \\
\hline & 0.05 & 7 & 1 & 14.3 & 3.4 \\
\hline \multirow[t]{3}{*}{5} & 0.01 & 19 & 3 & 15.8 & 6.3 \\
\hline & 0.03 & 10 & 1 & 10.0 & 3.4 \\
\hline & 0.05 & 10 & 1 & 10.0 & 2.4 \\
\hline \multirow[t]{2}{*}{7} & 0.01 & 9 & 1 & 11.1 & 3.2 \\
\hline & 0.03 & 4 & 1 & 25.0 & 1.4 \\
\hline \multicolumn{6}{|c|}{ O. sativa $\times O$ officinalis } \\
\hline \multirow[t]{3}{*}{3} & 0.01 & 25 & 5 & 20.0 & 3.5 \\
\hline & 0.03 & 18 & 3 & 16.7 & 6.0 \\
\hline & 0.05 & 13 & 3 & 23.1 & 4.2 \\
\hline \multirow[t]{3}{*}{5} & 0.01 & 15 & 4 & 26.7 & 4.2 \\
\hline & 0.03 & 9 & 2 & 22.2 & 6.5 \\
\hline & 0.05 & 7 & 1 & 14.3 & 3.6 \\
\hline \multirow[t]{2}{*}{7} & 0.01 & 7 & 1 & 14.3 & 3.4 \\
\hline & 0.03 & 4 & 1 & 25.0 & 3.9 \\
\hline
\end{tabular}

O. sativa $\times O$. minuta and $0.03 \%$ colchicine for 5 days of $O$. sativa $\times O$. officinalis. However, the seeds were slightly smaller than the $O$. sativa seeds.

In this experiment, cytological analysis indicated that the $\mathrm{F}_{1}$ hybrids of $O$. sativa $\times O$. minuta were allotriploid of the $\mathrm{ABC}$ genome $(2 \mathrm{n}=36)$ and $\mathrm{F}_{1}$ hybrids of $O$. sativa $\times O$. officinalis were allodiploid of the AC genome $(2 n=24)$ so they were all sterile. After doubling the chromosome num- ber by colchicine treatment, they became allohexaploid of AABBC genome $(2 n=72)$ and allotetraploid of the AACC genome $(2 n=48)$, respectively, and produced gametes having a complete set of chromosome. These plants were partially fertile and produced seed.

Our results indicated that colchicine treatment of the hybrids could make them fertile. The seeds of the colchicinetreated $\mathrm{F}_{1}$ plants had normal growth, profuse tillers, panicles 
and seed. Therefore, our next challenge is to cross them back to cultivated rice to make introgressive hybridization.

\section{Acknowledgement}

We are grateful to Prof. Dr. Franz Hoffmann, Department of Developmental and Cell Biology, University of California, Irvine for his critical review and valuable suggestions on the manuscript.

\section{Literature Cited}

Amanate-Bordeos, A.D., R.J.Nelson, N.P.Oliva, R.D.Dalmacio, H. Leung and L.A.Sitch (1991) Transfer of blast and bacterial blight resistance from Oryza minuta to O. sativa. In "Rice genetics II. Proceedings of the Second International Rice Genetics Symposium" International Rice Research Institute (ed.), Manila, Philippines. 237-246.

Amanate-Bordeos, A., L.A. Sitch, R. Nelson, R.D. Dalmacio, N.P. Oliva, H.Aswidinnoor and H.Leung (1992) Transfer of bacterial blight and blast resistance from the tetraploid wild rice Oryza minuta to cultivated rice, Oryza sativa. Theor. Appl. Genet. 84: 345-354.

Chu, Y.E. and H.I.Oka (1970) Introgression across isolating barriers in wild and cultivated Oryza species. Evolution 24: 344-355.

Cooper,D.C. and R.A.Brink (1944) Collapse of the seed following the mating of Hordeum jabatam $\times$ Secale cereale. Genetics 29: 370-390.

Khush,G.S., E.Bacalangco and T.Ogawa (1990) A new gene for resistance to bacterial blight from $O$. longistaminata. Rice Genet. Newsl. 7: 121-122.

Jena,K.K. and G.S.Khush (1989) Monosomic alien addition lines of rice: production, morphology, cytology and breeding behavior. Genome 32: 449-455.

Jena,K.K. and G.S.Khush (1990) Introgression of genes from Oryza officinalis Well ex Watt to cultivated rice, O. sativa L. Theor.
Appl. Genet. 80: 737-745.

Multani,D.S., K.K.Jena, D.S.Brar, B.G.delos Reyes, E.R.Angeles and G.S.Khush (1994) Development of monosomic alien addition lines and introgression of genes from Oryza australiensis Domin. to cultivated rice O. sativa L. Theor. Appl. Genet. 88: 102-109.

Murashige, T. and F.Skoog (1962) A revised medium for rapid growth and bioassays with tobacco tissue culture. Physiol. Plant. 15: 473-497.

Pongtongkam, P., P.Ratisoontorn, S.Suputtitada, S.Apisitwanich, S. Peyachoknagul, K. Klakhaeng and S.Nettasana (1997) Improvement of rice for brown plant hopper resistance through immature embryo culture. Proceedings of the $8^{\text {th }}$ SABRAO General Congress and the Annual Meeting of the Korean Breeding Society, Seoul, Korea. 303-304.

Sano, Y. and S.Kobayashi (1996) Genetic dissection of crossability in rice. In "Rice genetics III. Proceedings of the Third International Rice Genetics Symposium" Khush,G.S. (ed.), International Rice Research Institute, Manila, Philippines. 381-385.

Sitch,L.A., R.D.Dalmacio and G.O.Romero (1989) Crossability of wild Oryza species and their potential use for improvement of cultivated rice. Rice Genet. Newsl. 6: 58-60.

Sitch,L.A. and G.O.Romero (1990) Attempts to overcome prefertilization incompatibility in interspecific and intergeneric crosses involving Oryza sativa L. Genome 33: 321-327.

Suputtitada, S., T. Adachi, P. Pongtongkam, P. Ratisoontorn, S. Peyachoknagul, S.Apisitwanich, K.Klakhaeng, P.Rodrangboon and R.Lertvichai (1994) Rice improvement through tissue culture. Proceedings of the International Colloquium on Impact of Plant Biotechnology on Agriculture, Rogla, Slovenia. 73-84.

Suputtitada, S., T. Adachi, P. Pongtongkam, S. Peyachoknagul, S. Apisitwanich and J.Thongpradistha (2000) Breeding barriers in the interspecific cross of Oryza minuta Presl. Breed. Sci. 50: 29-35.

Vaughan,D.A. and L.A.Sitch (1991) Gene flow from the jungle to farmers: wild-rice genetic resources and their uses. Bio Science 41: 22-28. 